\title{
Metastases to extraocular muscles from breast cancer: case report and up-to-date review of the literature
}

\author{
Marialuisa Framarino-dei-Malatesta ${ }^{1,6^{*}} \mathbb{D}$, Annalisa Chiarito ${ }^{1}$, Federico Bianciardi ${ }^{2}$, Marco Fiorelli, ${ }^{3}$ Azzurra Ligato ${ }^{1}$,
} Giuseppe Naso ${ }^{4}$ and Irene Pecorella ${ }^{5}$

\begin{abstract}
Background: Unilateral or bilateral metastases to extraocular muscles are very rare in breast cancer.

Case presentation: We describe a case of inferior rectus extraocular muscle involved by ductal luminal B/Her2 neu negative breast cancer, observed in a cohort of 580 patients. Our patient had received chemotherapy and hormonal therapy (tamoxifen for 3 years and letrozole in the following 3 years) for her primary cancer and developed an orbital metastasis while she was under aromatase inhibitor-based therapy. Diagnosis was confirmed by MRI and biopsy. Orbital radiotherapy, combined with fulvestrant, resulted in shrinking of the secondary mass. A third line hormonal therapy using palbociclib was then started. Twelve-months later, MRI showed no residual tumor mass. Currently, the patient is alive and in good general conditions after 20 months.

Conclusions: Literature review yielded 57 patients with extraocular muscle metastases from breast cancer, mostly due to the invasive lobular subtype of carcinoma. In addition to the present case, only 4 other extraocular muscles metastases from invasive ductal carcinoma has been reported, pointing out to the rarity of ductal type spread to the orbit in the natural history of breast cancer. Surgery may be used as a single treatment, despite no improvement of symptoms. Radiotherapy alone or combined with chemotherapy, or with chemotherapy plus hormonal therapy are available options. Results are, however, missing or poor. The present case is the first one with complete and stable response after 20 months to radiotherapy, antiestrogen drug fulvestrant and selective inhibitor of CDK4 /CDK6 palbociclib. In this subset of patients, with unusual metastatic sites and frequent multi-organ metastatic impairment, a multidisciplinary approach is indicated in order to achieve the best therapeutic management and long-term surveillance.
\end{abstract}

Keywords: Extraocular muscles metastases, Breast cancer, Antiestrogen drug fulvestrant, Selective inhibitor of CDK4 /CDK6 palbociclib

\footnotetext{
* Correspondence: marialuisa.framarinodeimalatesta@uniroma1.it

${ }^{1}$ Department of Gynecological, Obstetrical, and Urological Sciences,

University Sapienza of Rome, Policlinico Umberto I, Viale del Policlinico 155,

00161 Rome, Italy

${ }^{6}$ Rome, Italy

Full list of author information is available at the end of the article
}

(c) The Author(s). 2019 Open Access This article is distributed under the terms of the Creative Commons Attribution 4.0 International License (http://creativecommons.org/licenses/by/4.0/), which permits unrestricted use, distribution, and reproduction in any medium, provided you give appropriate credit to the original author(s) and the source, provide a link to the Creative Commons license, and indicate if changes were made. The Creative Commons Public Domain Dedication waiver (http://creativecommons.org/publicdomain/zero/1.0/) applies to the data made available in this article, unless otherwise stated. 


\section{Background}

Orbital metastases may be the first sign of an undiagnosed primary tumor [1], mostly invasive lobular breast cancer (ILC), as the orbit represents a rich in fat niche which may attract disseminated ILC cells [2]. On the other hand, invasive ductal breast cancer (IDC) expresses E-cadherin, which limits cell dispersion and rarely brings to orbital metastases [3]. Unilateral or bilateral metastases to extraocular muscles are very rare [4], accounting for $9 \%$ of all orbital metastases [5]. Again, breast carcinoma (BC) and melanoma are mostly the primary source, though sometimes extraocular muscles involvement is the first manifestation of other underlying malignancies, such as renal cell carcinoma [6]. We describe a case of inferior rectus extraocular muscle metastasis observed in a cohort of 580 patients with histopathologically confirmed diagnosis of $\mathrm{BC}$, who attended our Oncological Day Hospital between January 1, 2011 and September 30, 2017. Additionally, we analyzed the prevalence and outcomes of these unusual metastases by literature review.

\section{Case presentation}

A 44 years-old woman presented with right breast pain, swelling and nipple retraction. Breast ultrasonography (US) showed an irregular hypoechoic mass $(30 \times 10 \mathrm{~mm})$ in the right retro-areolar space; a further lesion (maximum diameter $8 \mathrm{~mm}$ ) was detected in the right upper inner quadrant. Lymph-nodes with a maximum diameter of $25 \mathrm{~mm}$ were also detected in the right axilla by US. A core needle biopsy revealed a poorly differentiated (G3), estrogen receptor (ER) positive $(\mathrm{ER}+)$ [65\%], progesterone receptor $(\mathrm{PgR})$ positive $(\mathrm{PgR}+)[50 \%]$, cell proliferation antigen (Ki-67) 70\%, human epidermal growth factor receptor-2 (HER-2 neu) negative, IDC. A total body Computed Tomography (CT) showed no evidence of metastatic disease. After four cycles of neoadjuvant chemotherapy with epirubicin $100 \mathrm{mg} / \mathrm{m} 2$ and taxol 175 $\mathrm{mg} / \mathrm{m} 2$ every 21 days, a right "skin sparing" mastectomy and axillary lymph node dissection was performed. Immunohistochemistry confirmed G3 luminal B/HER-2 neu negative IDC subtype. Eleven out of fifteen axillary lymph nodes showed metastatic deposits (TNM: pT4b
N3a M0). After chest wall radiotherapy including supra -/infraclavicular lymphatic drainage area, the patient started further eight cycles of adjuvant chemotherapy with taxol $175 \mathrm{mg} / \mathrm{m} 2$ every 21 days. Tamoxifen $20 \mathrm{mg}$ daily and triptorelin $3,75 \mathrm{mg}$ once a month for 3 years, and letrozole $2.5 \mathrm{mg}$ daily in the following 3 years were used. Seven years after the diagnosis, while still under letrozole-based hormonal therapy, the patient displayed diplopia, blurred vision, and significantly restricted upward right eye movements (Fig. 1). Ocular acuity decreased from 7 to $2 / 10$ in both eyes. A brain Magnetic Resonance Imaging (MRI) showed a lump involving the right inferior rectus extraocular muscle (Fig. 2a). Computed Tomography (CT) confirmed this finding without showing other sites of metastasis. A transpalpebral biopsy revealed breast cancer metastasis (ER 50\%, PgR 0\%, Ki67 35\%, HER-2 neu negative) (Fig. 3). The patient underwent orbital Stereotactic Body Radiation Therapy (40 Gy in 5 days), combined with fulvestrant $500 \mathrm{mg}$ day 1, 15, 29 and, subsequently, every 28 days. A brain CT and MRI, performed 2 months later to evaluate the treatment response, showed a shrinking of the orbital mass. (Fig. 2b). One month after MRI, following mediastinal lymph nodes enlargement, a third line therapy using palbociclib $125 \mathrm{mg}$ daily for 3 weeks/month was started. Twelve-months later, MRI showed no residual tumor mass (Fig. 2c) and Positron Emission Tomography (PET) confirmed no uptake in the orbit. Despite tumor regression, the right eye sight failed to improve. Currently, the patient is alive and in good general conditions after 20 months under anti-hormonal-based therapy. Patient provided informed consensus to publish her case and release case details and other personal information and images.

\section{Discussion and conclusion}

In this review, we searched PubMed and Medline for English literature focusing on cases of extraocular muscle metastases from BC using the following search terms: breast cancer, orbital metastases and extraocular muscle metastases. Research articles, reviews and case reports were included.

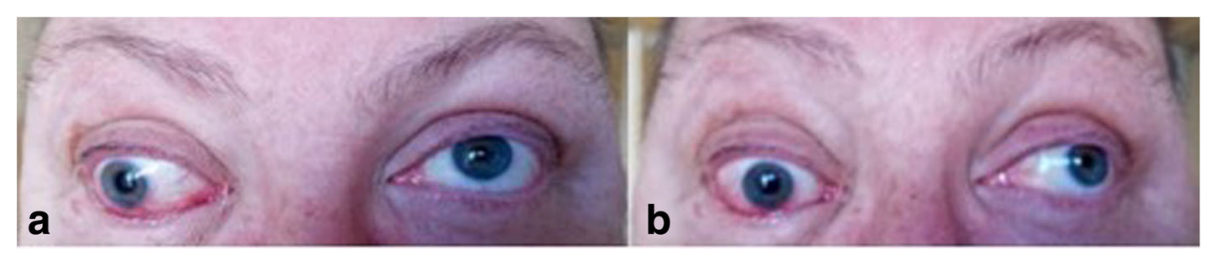

Fig. 1 51-year-old woman with right inferior rectus extraocular muscle from BC who was diagnosed with primary ductal BC (luminal B HER-2/neu negative pT4b N3a G3) 7 years earlier, with restricted upward right eye movements (a). Elevation and adduction of the right eye are restricted and there is right exophthalmos (b) 


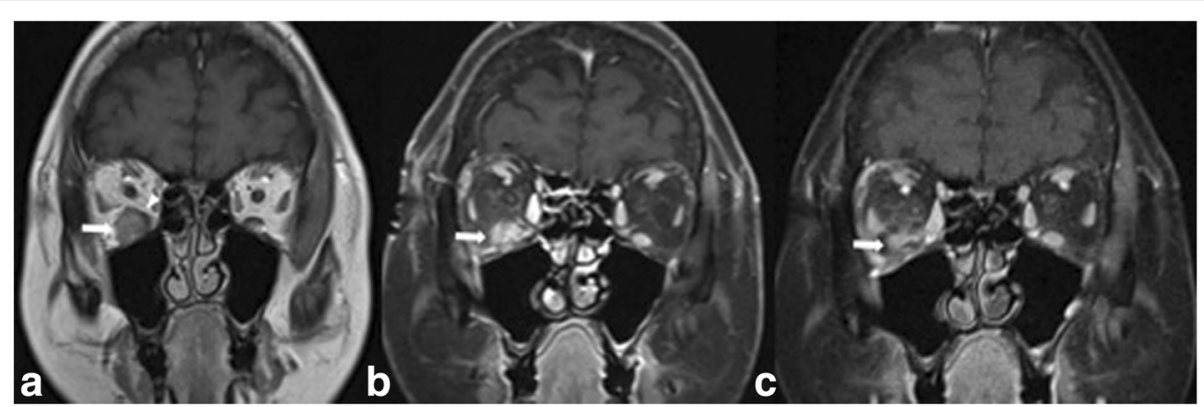

Fig. 2 a T1-weighted MR image depicting the lesion at the time of first diagnosis, as a slightly hyperintense solid nodule (arrow) located on the floor of the right orbit. Part of the belly of the inferior rectus muscle appears compressed and displaced (arrowhead). Post-contrast images were not acquired in this MR examination. b Post-contrast fat-suppressed T1-weighted image shows the shrinkage of the lesion (arrow) 2 months after the initiation of orbital radiotherapy followed by fulvestrant-based hormonotherapy. c Post-contrast fat-suppressed T1-weighted image shows further shrinkage of the lesion (arrow) 17 months after the initiation of radiotherapy + hormone therapy. Palbociclib was also added between $B$ and $\mathrm{C}$, see text for details). Right inferior rectus muscle is not discernible in (b) and (c). The maximum dimension of the lesion was 14 mm in $\mathrm{A}$, and decreased to $12 \mathrm{~mm} \ln \mathrm{B}$ and to $7 \mathrm{~mm}$ in (c)

Literature review yielded 57 patients with extraocular muscle metastases from BC [7-38]. Mean age was 60 years (range 40-83). Unfortunately, several studies did not provide histological subtypying of $\mathrm{BC}$, treatment details and overall survival data. Twelve patients had extraocular muscle metastases from ILC $[4,14,20,21$, $23,28,31,38]$, whereas in 5 patients (including our case) IDC was the primary source [29, 34-36]. Three patients had a poorly differentiated $\mathrm{BC}$, four patients had an undifferentiated $\mathrm{BC}$. Histology details were lacking in the remaining 34 patients. Unilateral muscle involvement was reported in 23 patients, including the present case, and bilateral involvement in 14, whereas in 21 women laterality was not specified. TC and/or MRI ascertained the diagnosis in 35 patients (including our case) and these results were subsequently confirmed at biopsy; in 12 cases autopsy or biopsy alone were conclusive. In 11 patients, biopsy was not performed. Single treatment was based on surgery in 4 patients, radiotherapy in 4 patients and hormonal therapy in 1. Combined treatments were used in 11 patients, as follows: chemo-radiotherapy in 6 , chemo-radiotherapy plus hormonal therapy with selective estrogen receptor modulators (SERMs) or aromatase inhibitors (AI) in 3, radiotherapy and hormonal therapy in 2. One of the 3 patients treated by chemo-radiotherapy plus hormonal therapy even received $47.5 \mathrm{~Gy}$ to the extraocular muscles without any signs of improvement. Therefore, whole-body hyperthermia was administered twice, combined with vinorelbine and mitomycin. Subsequently, she underwent several sessions of local hyperthermia and superficial hyperthermia on the skin metastases, 3 times a week. She died 1 month later without any information about her condition at that time [28]. No data about treatment were provided in 35 cases, and 2 patients did not receive any treatment. For the present case, we selected radiotherapy, hormonal therapy with antiestrogen drug fulvestrant and therapy with an oral, reversible, cyclindependent kinases 4/6 (CDK4/CDK6) inhibitor palbociclib. In 43 patients, the clinical outcome was not specified. In 11 cases, partial improvement and in 2 instances no response after single or combined treatments were reported. Fenton et al. described another case with lateral rectus relapsing metastasis from $\mathrm{BC}$, confirmed

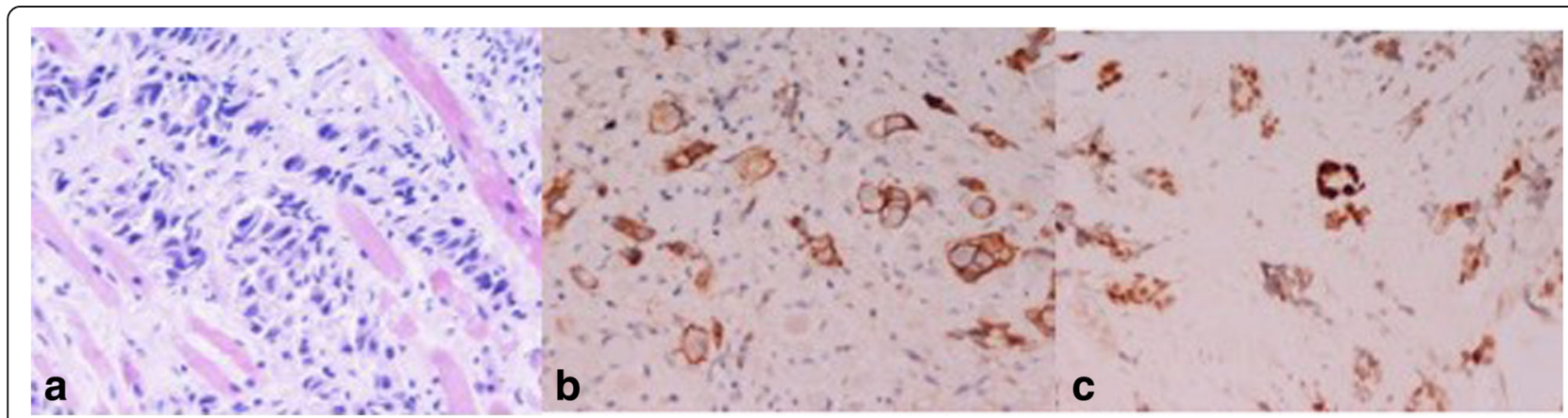

Fig. 3 Histology shows invasion of striated muscle fibers by ductal $B C(H \& E, 100 x)$ (a). The tumor cells are immunostained with antibodies directed against-cadherin (b) and ER (c), thus confirming their breast origin (avidin-biotin, AEC counterstain, $400 \times$ and $250 \times$, respectively) 
on CT scan and biopsy. Both first metastasis and relapse 2 years later were treated by orbital radiotherapy. She had been asymptomatic until her screening ophthalmic examination [24]. Our patient is the first case of full recovery following radiotherapy plus fulvestrant and palbociclib. A 4-months to 6-years overall survival was reported in 11 patients, while in 46 patients, survival data were missing. Table 1 provides clinical and histological data, treatments, outcomes and overall survival of all of the published cases included in the review.

Metastases to extraocular muscles belong to orbital metastases, the latter with an overall incidence ranging from 1 to $13 \%$ out of all metastatic cancers [33]. In 1990, Capone et al. made a thorough review of secondary malignancies from all over the body in this unusual site [18]. Our review is, on the other hand, the first up-to-date review on extraocular muscles metastases from breast cancer. It is not fully understood why metastatic cancers are rarely seen in voluntary muscles. The constant movement of muscles could prevent the neoplastic cell deposit or produce an unsuitable chemical environment for continued neoplastic growth [9]. ILC is the more frequent histological subtype involving extraocular muscles.

We have examined the impact of these metastases in our cohort of 580 patients with histopathologically confirmed diagnosis of $\mathrm{BC}$, who attended our Oncological Day Hospital between January,2011 and September,2017.

Data of 580 patients with invasive BC including patient's age, clinical presentation and interval between diagnosis of primary cancer and metastases were extracted from our Database. We also noted Immunohistochemical analysis of the primary cancer, as well as treatment modalities and outcomes. Sixty-two of our 580 breast cancer patients $(10.7 \%)$ developed metastases over a period of 6 to 168 months from diagnosis (mean value: 37 months). The patients' age ranged from 23 to 83 years (mean value: 58 years). Clinical presentation included: breast pain (80\%); partial or full swelling of the breast (70\%); skin irritation (50\%); nipple retraction (35\%); nipple discharge (15\%). HIC parameters according to Blows data [39] showed "luminal A" breast cancer subtype in 22 patients, "luminal B HER-2 neu positive" subtype in 17 patients, "luminal B HER-2 neu negative" subtype in 12 patients; "no luminal HER-2 neu positive" subtype in 6 patients and "triple negative" subtype in 5 patients. Distribution of metastatic sites in relation to histological and immunohistochemical subtypes is summarized in Table 2.

Bone metastases developed in 30 patients $(48,3 \%)$, liver metastases in 11 (17.7\%), lung metastases in $17(27,4 \%)$ and brain metastases in $3(4.8 \%)$. Our data are consistent with a recent retrospective study by $\mathrm{Z}$. Chen et al. including 796,335 patients with BC. In our series, bone metastases from ILC were most common than IDC (91.52 and $76.04 \%$, respectively). In the ILC group, the second most common metastatic site was the liver (19.64\%), followed by the lung (13.61\%) and brain $(4.23 \%)$, while in the IDC group it was the lung (37.11\%), followed by the liver (30.53\%) and brain $(8.24 \%)$ [40]. Only one case of IDC in our cohort was associated with an extraocular muscle metastasis and represents the fifth described case of such involvement, pointing out to its rarity in the natural history of IDC.

From the clinical point of view, diplopia and motility disturbances are the most common symptoms and signs of extraocular muscle secondaries. Palpable or visible mass, ocular proptosis or displacement are also common. Pain and inflammatory signs, such as swelling and chemosis, are seen in less than one quarter of patients [17]. Local pain is described in all patients with metastases involving orbital and ocular regions [20]. Histology of the lump confirms the diagnosis. The horizontal rectus muscles are more commonly affected than the vertical and oblique ones [41], as in our patient. Metastases to the extraocular muscles can be detected by US, MRI and CT scan. The latter is known to detect more than $95 \%$ of the orbital tumors and to provide clinical information about the size, quadrant location, relation to muscle cone and other structures [28]. MRI, compared to $\mathrm{CT}$, offers sometimes better resolution of the mass [9], as in our case. As extraocular metastases from BC usually occur in the setting of multisystem end-stage disease, the treatment is mainly palliative $[14,25]$. Surgery may be used as a single treatment $[9,10,21,22]$, despite no improvement of symptoms [12]. Radiation therapy alone (usually $30 \mathrm{~Gy}$ ) [16, 24, 34, 35], combined with chemotherapy, $[11,13,32]$ or with chemotherapy plus hormonal therapy $[19,25,28]$ are available options. Single hormonal therapy has been reported [29]. AIs (anastrozole, letrozole, exemestane) are now recognized as the agents of choice for the management of post-menopausal women with steroid hormone positive metastatic BC, in whom indications for chemotherapy are not absolute [42]. Fulvestrant, a competitive estrogen receptor antagonist with comparable affinity to estradiol, is a safe and active treatment for endocrine sensitive advanced $\mathrm{BC}$ patients [43]. Alterations in the mechanisms governing the cell cycle induces uncontrolled cellular proliferation and CDK4/6 are recognized as potential target in ER+ BC [44]. Recently palbociclib, a selective inhibitor of CDK4 /CDK6, received a 'Breakthrough Therapy' designation from the US FDA in metastatic ER + breast cancer [45]. Paloma 3 trial established a longer progression-free survival from association of palbociclib combined with fulvestrant as second-line treatment for ER+, HER2-negative advanced or metastatic BC with 


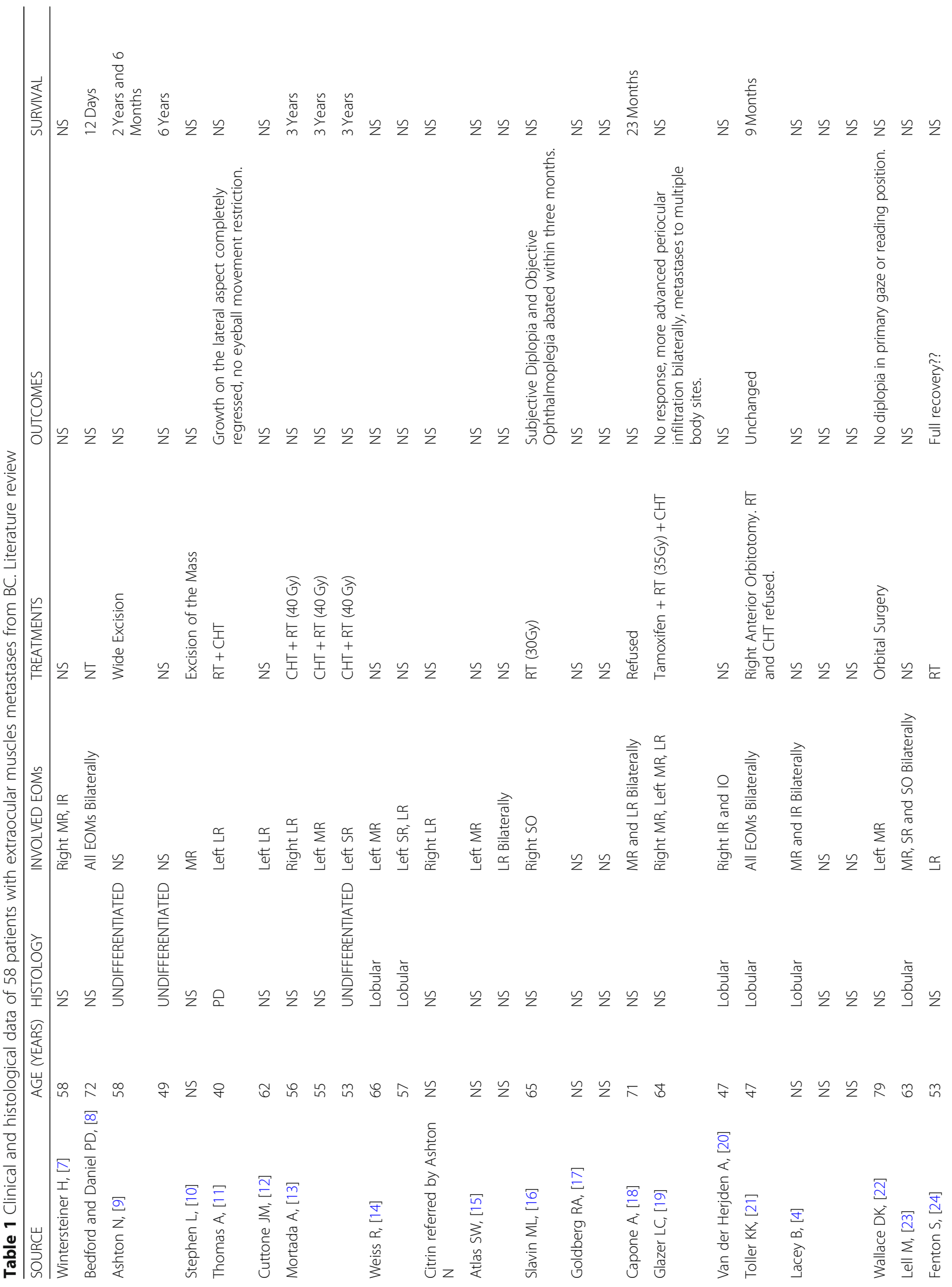




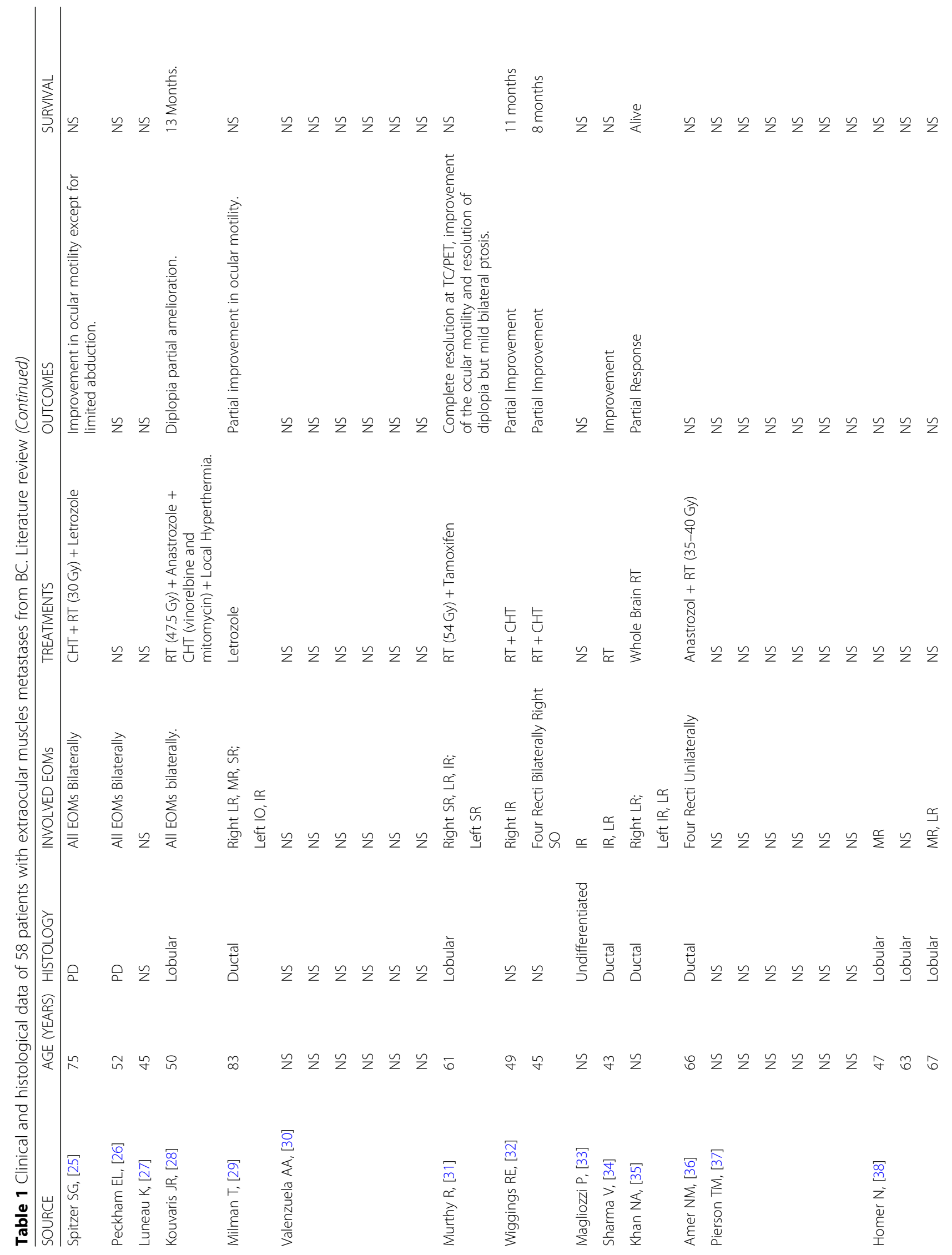




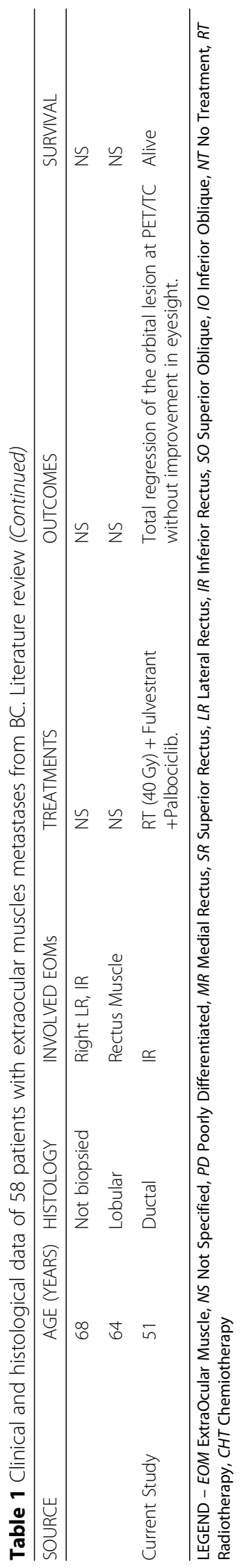


Table 2 Distribution of metastatic sites in relation to histological and immunohistochemical subtypes in a cohort of 62 patients

\begin{tabular}{|c|c|c|c|c|c|c|c|}
\hline \multirow[t]{2}{*}{ HYSTOLOGY } & \multirow[t]{2}{*}{$\mathrm{IHC}$} & \multicolumn{5}{|c|}{ METASTATIC SITES } & \multirow[t]{2}{*}{ TOTAL } \\
\hline & & Lung & Liver & Bone & Brain & EOM & \\
\hline \multirow[t]{5}{*}{ DUCTAL } & LUMINAL A & 2 & 1 & 6 & 0 & 0 & 9 \\
\hline & LUMINAL B HER2 - & 3 & 3 & 9 & 0 & 1 & 16 \\
\hline & LUMINAL B HER2 + & 3 & 3 & 3 & 1 & 0 & 10 \\
\hline & NO LUMINAL HER2 + & 3 & 2 & 1 & 2 & 0 & 8 \\
\hline & TRIPLE NEGATIVE & 5 & 1 & 4 & 0 & 0 & 10 \\
\hline \multirow[t]{5}{*}{ LOBULAR } & LUMINAL A & 1 & 1 & 3 & 0 & 0 & 5 \\
\hline & LUMINAL B HER2 - & 0 & 0 & 2 & 0 & 0 & 2 \\
\hline & LUMINAL B HER2 + & 0 & 0 & 1 & 0 & 0 & 1 \\
\hline & NO LUMINAL HER2 + & 0 & 0 & 0 & 0 & 0 & 0 \\
\hline & TRIPLE NEGATIVE & 0 & 0 & 1 & 0 & 0 & 1 \\
\hline TOTAL & & 17 & 11 & 30 & 3 & 1 & 62 \\
\hline
\end{tabular}

IHC Immunohistochemistry, EOM Extraocular Muscles

adata only include the first site of metastatic disease

disease progression during or following endocrine therapy $[46,47]$.

According to these recent advances in metastatic $\mathrm{BC}$ we decided to use radiotherapy for local disease control, third-line hormonal therapy with fulvestrant that followed previous tamoxifen and letrozol treatments and selective inhibitor of CDK4 /CDK6 palbociclib for control of systemic disease, with good results so far.

The present case is the fifth IDC involving extraocular muscles, and the first with complete and stable response to radiotherapy, antiestrogen drug fulvestrant and palbociclib, in the absence of short-term side effects. We also wish to underline that these metastases are very rare and frequently are part of systemic metastatic disease from BC. In this subset of patients, rarity of the involved site and frequent multi-organ neoplastic impairment indicate a multidisciplinary approach in order to achieve the best therapeutic management. Long-term surveillance will be required to establish effective remission and any long-term side effects.

\section{Abbreviations \\ Als: Aromatase inhibitors; BC: Breast carcinoma; CD4/6: Cyclin-dependent kinases 4/6; CHT: Chemiotherapy; CT: Computed Tomography; EOM: ExtraOcular Muscle; EOMMs: Extraocular muscles metastases; ER: Estrogen receptor; ER+: Estrogen receptor positive; HER-2 neu: Human epidermal growth factor receptor-2; HIC: Immunohistochemistry; IDC: Ductal invasive breast cancer; ILC: Lobular invasive breast cancer; IO: Inferior Oblique; IR: Inferior Rectus; Ki-67: Cell proliferation antigen; LR: Lateral Rectus; MR: Medial Rectus; MRI: Magnetic Resonance Imaging; NS: Not Specified; NT: No Treatment; PD: Poorly Differentiated; PET: Positron Emission Tomography; PgR: Progesterone receptor; PgR+: Progesterone receptor positive; RT: Radiotherapy; SERMs: Selective estrogen receptor modulators; SO: Superior Oblique; SR: Superior Rectus; US: Ultrasonography}

\section{Funding}

No funding to declare.

\section{Availability of data and materials}

The patient's medical record is kept at the Department of Gynecology, Obstetrics and Urological Science. MR images are stored at the Department of Neurosciences. Histological data are stored at the Department of Radiological, Oncological and Anatomical Pathology Sciences. University Sapienza Rome. Policlinico Umberto I, Viale del Policlinico 155, 00161 Rome, Italy.

\section{Authors' contributions}

MFdM made conception and design of the paper, interpretation of data and drafted manuscript. AC, AL, IP made substantial contribution to acquisition of and analysis of data. IP, MF, GN, FB was involved in critically revising the manuscript for important intellectual content. All Authors give final approval of the version to be published. Each author should have participated sufficiently in the work to take public responsibility for appropriate portions of the content; and agreed to be accountable for all aspects of the work in ensuring that questions related to the accuracy or integrity of any part of the work are appropriately investigated and resolved. All authors read and approved the final manuscript.

Ethics approval and consent to participate

Not applicable.

\section{Consent for publication}

Written informed consent was obtained from the patient for publication of this Case report and any accompanying images.

\section{Competing interests}

The authors declare that they have no competing interests.

\section{Publisher's Note}

Springer Nature remains neutral with regard to jurisdictional claims in published maps and institutional affiliations.

\section{Author details}

${ }^{1}$ Department of Gynecological, Obstetrical, and Urological Sciences, University Sapienza of Rome, Policlinico Umberto I, Viale del Policlinico 155, 00161 Rome, Italy. ${ }^{2}$ Radiotherapy - UPMC San Pietro Fatebenefratelli, Via Cassia 600, 00189 Rome, Italy. ${ }^{3}$ Department of Neurosciences, University Sapienza of Rome, Policlinico Umberto I, Viale dell'Universita' 30, 00185 Rome, Italy. ${ }^{4}$ Department of Radiological, Oncological and Anatomical Pathology Sciences, University Sapienza of Rome, Policlinico Umberto I, Viale del Policlinico 155, 00161 Rome, Italy. ${ }^{5}$ Department of Radiological, Oncological and Anatomical Pathology Sciences, University Sapienza of Rome, Viale Regina Elena 324 -, 00161 Rome, Italy. ${ }^{6}$ Rome, Italy. 
Received: 17 April 2018 Accepted: 26 December 2018

\section{Published online: 08 January 2019}

\section{References}

1. Tomizawa Y, Ocque R, Ohori NP. Orbital metastasis as the initial presentation of invasive lobular carcinoma of breast. Intern Med. 2012; 51(12):1635-8 Epub 2012 Jun 15.

2. Raap $M$, Antonopoulos W, Dämmrich $M$, Christgen $H$, Steinmann D, Länger $F$, et al. High frequency of lobular breast cancer in distant metastases to the orbit. Cancer Med. 2015;4(1):104-11. https://doi.org/10.1002/cam4.331 Epub 2014 Oct 30. Review.

3. Jakobiec F, Stagner A, Homer N, Yoon M. Periocular breast carcinoma metastases: predominant origin from lobular variant. Ophthal Plast Reconstr Surg. 2017;33(5):361-6. https://doi.org/10.1097/IOP.0000000000000793.

4. Lacey B, Chang W, Rootman J. Nonthyroid causes of extraocular muscle disease. Surv Ophthalmol. 1999;44(3):187-213 Review. 44:187-213.

5. Shields JA, Shields CL, Brotman HK, Carvalho C, Perez N, Eagle RC Jr. Cancer metastatic to the orbit, the 2000 Robert M. Curts Lecture. Ophthal Plast Reconstr Surg. 2001;17(5):346-54 17:346-54.

6. Slamovits TL, Burde RM. Bumpy muscles. Surv Ophthalmol. 1988;33(3):189-99.

7. Wintersteiner $\mathrm{H}$, von Augen EF. Muskel Metastasen nach carcinoma Mammae. Klin Monatsbl Augenheilkd Augenaerztliche. 1899;37:331-8.

8. Bedford PD, Daniel PM. Discrete carcinomatous metastases in the extrinsic ocular muscles: a case of carcinoma of the breast with exophthalmic ophthalmoplegia. Am J Ophthalmol. 1960;49:723-6.

9. Ashton N, Morgan G. Discrete carcinomatous metastases in the extraocular muscles. Br J Ophthalmol. 1974;58(2):112-7.

10. Trokel SL, Hilal SK. Recognition and differential diagnosis of enlarged extraocular muscles in computed tomography. Am J Ophthalmol. 1979; 87(4):503-12.

11. Thomas A, Oomen MM, Sudarsanam D, Singh AD. Metastatic carcinoma breast in lateral rectus muscle. Indian J Ophthalmol. 1979;27(1):23-4

12. Cuttone JM, Litvin J, JE MD. Carcinoma metastatic to an extraocular muscle. Ann Ophthalmol. 1981;13(2):213-6.

13. Mortada A. Binocular diplopia due to metastasis in orbital muscle from female breast cancer years after radical mastectomy. Orbit. 1984;3:71-3 Published online 8 July 2009.

14. Weiss R, Grisold W, Jellinger K, Mühlbauer J, Scheiner W, Vesely M. Metastasis of solid tumors in extraocular muscles. Acta Neuropathol. 1984; 65(2):168-71.

15. Atlas SW, Grossman RI, Savino PJ, Sergott RC, Schatz NJ, Bosley TM, et al. Surface-coil MR of orbital pseudotumor. Am J Roentgenol. 1987; 148(4):803-8.

16. Slavin ML, Goodstein S. Acquired Brown's syndrome caused by focal metastasis to the superior oblique muscle. Am J Ophthalmol. 1987;103(4): 598-9.

17. Goldberg RA, Rootman J, Cline RA. Tumors metastatic to the orbit: a changing picture. Surv Ophthalmol. 1990:35(1):1-24 Review.

18. Capone A Jr, Slamovits TL. Discrete metastasis of solid tumors to extraocular muscles. Arch Ophthalmol. 1990;108(2):237-43.

19. Glazer LC, Harris GJ, Simons KB. Orbital metastasis as the presenting sign of adenocarcinoma of the breast. Ophthal Plast Reconstr Surg. 1991;7(4):252-5.

20. van der Heijden A, Twijnstra A, Lamers WP, Hupperets PS, Freling G. An unusual cause of diplopia in a cancer patient. Eur J Cancer. 1991;27(10): 1315-6

21. Toller KK, Gigantelli JW, Spalding MJ. Bilateral orbital metastases from breast carcinoma. Ophthalmology. 1998;105(10):1897-901.

22. Wallace DK, Virata SR, Mukherji SK. Strabismus surgery complicated by "pulled in two syndrome" in a case of breast carcinoma metastatic to the medial rectus muscle. J AAPOS. 2000;4(2):117-9.

23. Lell M, Schulz-Wendtland R, Hafner A, Magener A, Bautz WA, Tomandl BF. Bilateral orbital tumor as the presentation of mammographically occult breast cancer. Neuroradiology. 2004;46(8):682-5 Epub 2004 Jul 8.; 46: 682-5.

24. Fenton S, Kemp EG, Harnett AN. Screening for ophthalmic involvement in asymptomatic patients with metastatic breast carcinoma. Eye. 2004;18(1): 38-40.

25. Spitzer SG, Bersani TA, Mejico LJ. Multiple bilateral extraocular muscle metastases as the initial manifestation of breast cancer. J Neuro-Oncol. 2005;25(1):37-9.

26. Peckham EL, Giblen G, Kim AK, Sirdofsky MD. Bilateral extraocular metastasis from primary breast cancer. Neurology. 2005;65(1):74.
27. Luneau K, Falardeau J, Hardy I, Boulos PB, Boghen D. Ophthalmoplegia and lid retraction with normal initial orbit $C T$ imaging in extraocular muscle metastases as the presenting sign of breast carcinoma. J Neuroophthalmol. 2007;27(2):144-6.

28. Kouvaris JR, Gkongkou PV, Papadimitrou CA, Papacharalampous XN, Antypas CE, Balaforta MJ, et al. Bilateral metastasis to extraocular muscles from lobular breast carcinoma. Onkologie. 2008;31(7):387-9. https://doi.org/10. 1159/000129689 Epub 2008 Jun 16. Review.

29. Milman T, Pliner L, Langer PD. Breast carcinoma metastatic to the orbit: an unusually late presentation. Ophthal Plast Reconstr Surg. 2008;24(6):480-2. https://doi.org/10.1097/IOP.0b013e31818b6adc.

30. Valenzuela AA, Archibald CW, Fleming B, Ong L, O'Donnell B, Crompton JJ, et al. Orbital metastasis: clinical features, management and outcome. Orbit. 2009;28(2-3):153-9.

31. Murthy R, Gupta A, Hegde S, Honavar SG. Bilateral multiple extraocular muscle metastasis from breast carcinoma. Indian J Ophthalmol. 2011; 59(5):381-2.

32. Wiggings RE, Byrne SF. Metastatic tumor to the extraocular muscles: report of 5 cases. JAAPOS. 2012;16(5):489-91. https://doi.org/10.1016/j.jaapos.2012.06.009.

33. Magliozzi $P$, Strianese $D$, Bonavolontà $P$, Ferrara $M$, Ruggiero $P$, Carandente R, et al. Orbital metastases in Italy. Int J Ophthalmol. 2015;8(5):1018-23. https://doi.org/10.3980/j.issn.2222-3959.2015.05.30 eCollection 2015.

34. Sharma V, Bhardwaj R, Chaudhary KP, Pandey ML, Sharma S. A case of metastatic infiltrating ductal breast carcinoma with initial metastases to the optic nerve and subsequent extra ocular muscle involvement. Indian J Cancer. 2015;52(3):275-6. https://doi.org/10.4103/0019-509X.176757.

35. Khan NA, Morlese J, Khan A. Radiological foresight: a rare case of breast cancer metastases to the extraocular muscles. BMJ Case Rep. 2015. https:// doi.org/10.1136/bcr-2015-211264.

36. Amer NM, Bashir G, Ogedegbe A, Saeed I. Metastatic breast cancer: an unusual cause of diplopia. J Cancer Metastasis Treat. 2016;4(2):123-6.

37. Pierson TM, Tebit EV, Sayed AE, Smolkin ME, Dillon PM. Orbital metastases from breast cancer: retrospective analysis at an academic cancer center. The Brest Journal. 2016;22(4):447-50. https://doi.org/10.1111/tbj.12604 Epub 2016 May 3

38. Homer N, Jakobiec FA, Stagner A, Cunnane ME, Freitag SK, Fay A, et al. Periocular breast carcinoma metastases: correlation of clinical, radiologic and histopathologic features. Clin Exp Ophthalmol. 2017:45(6):606-12. https://doi.org/10.1111/ceo.12926 Epub 2017 Mar 3.

39. Blows FM, Driver KE, Schmidt MK, Broeks A, van Leeuwen FE, Wesseling J, Cheang MC, Gelmon K, Nielsen TO, Blomqvist C, Heikkila P, Heikkinen T, Nevanlinna H, Akslen LA, Begin LR, Foulkes WD, Couch FJ, Wang X, Cafourek V, Olson JE, Baglietto L, Giles GG, Severi G, CA ML, Southey MC, Rakha E, Green AR, Ellis 1O, Sherman ME, Lissowska J, Anderson WF, Cox A, Cross SS, Reed MW, Provenzano E, Dawson SJ, Dunning AM, Humphreys M, Easton DF, Garcia-Closas M, Caldas C, Pharoah PD, Huntsman D. Subtyping of breast cancer by immunohistochemistry to investigate a relationship between subtype and short and long term survival: a collaborative analysis of data for 10,159 cases from 12 studies. PLoS Med. 2010;7:e1000279.

40. Chen Z, Yang J, Li S, Lv M, Shen Y, Wang B, et al. Invasive lobular carcinoma of the breast: a special histological type compared with invasive ductal carcinoma. PLoS One. 2017;12(9):e0182397. https://doi.org/10.1371/journal. pone.0182397 eCollection 2017.

41. Croxatto OJ, Karcioglu ZA. Metastatic tumors. In: Karcioglu ZA, editor. Orbital tumors: diagnosis and treatment: Springer; 2015. p. 321-35. https://doi.org/ 10.1007/978-1-4939-1510-1.

42. Flaum LE, Gradishar WJ. Advances in endocrine therapy for postmenopausal metastatic breast Cancer. Cancer Treat Res. 2018;173:141-54. https://doi.org/ 10.1007/978-3-319-70197-4_9.

43. Moscetti L, Fabbri MA, Natoli C, Vici P, Gamucci T, Sperduti I, et al. Fulvestrant 500 milligrams as endocrine therapy for endocrine sensitive advanced breast cancer patients in the real world: the Ful500 prospective observational trial. Oncotarget. 2017;8(33):54528-36. https://doi.org/10. 18632/oncotarget.17262 eCollection 2017 Aug 15.

44. Hanahan D, Weinberg RA. Hallmarks of cancer: the next generation. Cell. 2011;144:646-74. https://doi.org/10.1016/j.cell.2011.02.013.

45. FDA approves Ibrance for postmenopausal women with advanced breast cancer. https://www.fda.gov/drugs/informationondrugs/approveddrugs/ ucm549978.htm. Accessed 30 Dec 2018.

46. Turner NC1, Ro J, André F, Loi S, Verma S, Iwata H, et al. PALOMA3 Study Group. Palbociclib in Hormone-Receptor-Positive Advanced Breast Cancer. N 
Engl J Med. 2015;373(3):209-19. https://doi.org/10.1056/NEJMoa1505270 Epub 2015 Jun 1.

47. Iwata H, Im SA, Masuda N, Im YH, Inoue K, Rai Y, et al. PALOMA-3: phase III trial of Fulvestrant with or without Palbociclib in premenopausal and postmenopausal women with hormone receptor-positive, human epidermal growth factor receptor 2-negative metastatic breast Cancer that progressed on prior endocrine therapy-safety and efficacy in Asian patients. J Glob Oncol. 2017;3(4):289-303. https://doi.org/10.1200/JGO.2016.008318. eCollection 2017 Aug.

- fast, convenient online submission

- thorough peer review by experienced researchers in your field

- rapid publication on acceptance

- support for research data, including large and complex data types

- gold Open Access which fosters wider collaboration and increased citations

- maximum visibility for your research: over $100 \mathrm{M}$ website views per year

At BMC, research is always in progress. 